\title{
AVALIAÇÃO DA RESISTÊNCIA AO ARRANCAMENTO EM SOLO GRAMPEADO ATRAVÉS DE FASES DE INJEÇÃO
}

\author{
Evaluation of resistance pullout tests to soil mailing through injection phases
}

\author{
Rodrigo Rogério Cerqueira da Silva ${ }^{1}$
}

Recebido em 13 de dezembro de 2017; aceito em 09 de julho de 2018; disponível on-line em 26 de maio de 2019.

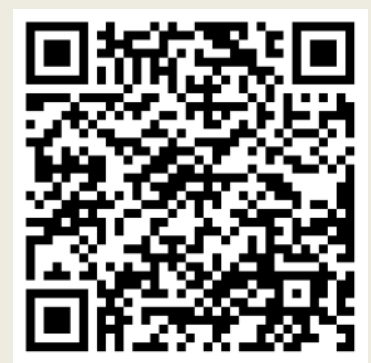

\section{PALAVRAS CHAVE:}

Solo grampeado;

Ensaio de arrancamento; Injeção de calda; Instrumentação, Solos coesivos.

\section{KEYWORDS:}

Soil Nailing;

Pullout Tests;

Grout Injection;

Intrumentation;

Cohesive soils

\section{* Contato com o autor:}

${ }^{1}$ e-mail: rodrigorogeriomestrado@yahoo.com.br (R. R. C. Silva )

Mestrado Construção Civil, Professor de Engenharia Civil da Universidade Nove de Julho, Coordenador Técnico GEOBASE Geotecnia e Fundações Especiais .
RESUMO: A técnica de estabilização de encostas por meio do solo grampeado, vem tornando-se no meio geotécnico sinônimo de contribuição financeira através da injeção de fases, generalizando este tipo de metodologia para todas estratigrafias de solos, aumentando o valor das obras executas em taludes devido a cobrança do volume de calda de cimento injetada, distanciando de sua metodologia original através da rápida contenção em maciços de solo. O escopo da pesquisa é apresentar os parâmetros de resistência ao cisalhamento da interface solo-grampo (qs), realizados a partir de ensaios de arrancamento e fluência em três chumbadores com diferentes fases de injeção e consumo de calda de cimento, em uma obra de infraestrutura localizada em São Paulo. Os resultados permitiram quantificar que a injeção através do preenchimento anelar entre barra e furo (bainha) é fundamental para sua fixação, mobilizando pequenos deslocamentos em relação a carga máxima de ensaio, demonstrando que a adesão solo-estrutura pode ser comprometida pela quantidade de tubos manchetados. Verificando que o preenchimento anelar é fundamental na adesão dos chumbadores e no tratamento para reduzir as infiltrações através das feições geológicas de baixas permeabilidades, quando executados em solos coesivos. Analisando que para cada tipo de solo e obra a ser executada existe uma aderência e limite de injetabilidade compatível com as resistências mecânicas do solo que o chumbador será ancorado.

ABSTRACT: The technique of stabilization of slopes by means of stapled soil, has become in the geotechnical environment synonymous with financial contribution through the injection of phases, generalizing this type of methodology for all stratigraphies of soils, increasing the value of the works executed in slopes due to the collection of the volume of injected cement, distancing from its original methodology through the rapid containment in soil masses. The scope of the research is to present the parameters of shear strength of the soil-clamp interface (qs), performed from pullout and creep tests on three anchor bolts with different injection phases and cement mix consumption, in an infrastructure work located in São Paulo. The results allowed to quantify that the injection through the annular filling between the rod and the sheath (sheath) is fundamental for its fixation, mobilizing small displacements with respect to the maximum test load, demonstrating that soil-structure adhesion can be compromised by the number of stamped tubes. Verifying that ring fill is fundamental in the adhesion of the anchors and in the treatment to reduce the infiltrations through the geological features of low permeabilities, when executed in cohesive soils. Analyzing that for each type of soil and work to be executed there is an adhesion and limit of injection compatible with the mechanical resistance of the ground that the anchor will be anchored. 


\section{INTRODUÇÃO}

Atualmente profissionais da área de engenharia geotécnica se deparam com o fato de que não há uma norma técnica propriamente dita para o uso de solo grampeado de forma a esclarecer dúvidas, indicar boas práticas de projeto e parâmetros a serem ponderados, levando a técnica a diferentes tipos de execução. A concepção de chumbadores na última década vem se distanciando da técnica desenvolvida por Rabcewicz (1964), através do sistema rápido de contenção para execução de suportes de galerias e túneis denominada NATM (New Austrian Tunneling Method), aplicada na engenharia de minas aonde barras de aço são inseridas no maciço por perfuração com posterior injeção de nata de cimento. A técnica busca formar um maciço estável de contenção, semelhante a um muro de gravidade, quando as nervuras são executadas inclinadas aumentando a resistência ao cisalhamento do solo através de seu trabalho de tração.

Esta técnica vem recebendo a prática comum independente do tipo de solo a padronização da instalação próxima às barras de aço tubos de injeção de calda de cimento, necessitando da análise do principal parâmetro técnico a adesão (qs), responsável pelo mecanismo de transferência de carga na interface entre elemento de tração e solo circundante, restringindo movimentação de maciços de solos.

A presente pesquisa contempla em um programa experimental realizado em uma obra de infraestrutura localizada em Guarulhos município de São Paulo, contribuindo para o estabelecimento de uma metodologia de execução condizente as características geológicas geotécnicas locais, promovendo dados provenientes em ensaios de arrancamento em chumbadores submetidos a diferentes quantidades de injeção de calda de cimento. Com isso o solo grampeado que tem como contribuição geotécnica seu baixo custo, versatilidade de adaptação à geometrias variadas, alta velocidade de execução e aplicação, passou a representar alto custo financeiro devido ao maior tempo de execução, volume de calda para cada fase de injeção, além do consumo excessivo de materiais.

Desta forma para taludes ou escavações íngremes com solo de baixa permeabilidade, a aplicação de chumbadores será mais econômica desconsiderando a necessidade de reinjeção, observada através do seu comportamento mecânico, contribuindo com uma interação fisicoquímica entre chumbador e solo, devido a injeção de fixação da barra de aço no furo obter maior trabalho por atrito e adesão. Considerando a experiência do executor, o acompanhamento da execução e á análise de instrumentação, elementos condicionantes na definição do projeto para injeção ou não de fases.

\section{OBJETIVO}

O objetivo da presente pesquisa é avaliar a influência das diferentes metodologias de injeção de calda de cimento em solo grampeado, através da interface solo-reforço, fornecendo uma base de dados para projetos geotécnicos através do ensaio de arrancamento e fluência, visando a possibilidade de aprimorar a técnica de estabilização de encostas e reduzir os custos obtidos in loco, através do consumo excessivo de calda de cimento.

\section{PARÂMETROS QUE CONTRIBUEM PARA ADESÃO SOLO-REFORÇO}

\subsection{CARACTERÍSTICA DA CALDA DE CIMENTO}

As caldas comumente usadas para execução de chumbadores são constituídas basicamente de cimento e água, onde eventualmente para melhorar as suas características de estabilidade e injeção, pode-se adicionar algum tipo de aditivo (acelerador ou retardador) em função das condições climáticas. Esses aditivos devem ser utilizados após 
a realização de ensaios que comprovem a sua melhoria na qualidade da calda, não devendo conter substâncias agressivas (fluidificantes, redutor de água, retardadores e expansor), ao aço o principal elemento dos chumbadores.

Ensaios realizados por Silva (2011) demonstram que as caldas de cimento podem variar sua resistência ligeiramente em decorrência das diversas marcas de cimento e tipos de aditivos. A principal condicionante que afeta as propriedades das injeções é a relação $A / C$ (água/cimento), pois o excesso de água causa exsudação a qual reduz a resistência, aumenta a retração, porosidade e diminui a durabilidade dos chumbadores. Sendo assim, diversos aspectos devem ser considerados para preparação e estabelecimento dos traços das caldas, como: o fator A/C, vida útil, exsudação, expansão, resistência a compressão, materiais e dosagem.

A análise do desempenho da injeção de calda de cimento pode utilizar os conceitos introduzidos por Azevedo et. al (1978), o qual baseia-se no comportamento geológico do maciço, e através dos procedimentos técnicos, como: linhas de injeção, espaçamento entre os furos, pressões de injeção, tipos de calda e critério de recusa da calda de cimento. Para cada tipo de calda e para cada tipo de trabalho a ser efetuado existe um limite de injetabilidade, capacidade da calda penetrar no meio a ser injetado, sendo que a melhor deverá ser compatível com as resistências mecânicas que a calda deverá oferecer.

Weaver e Bruce (2007) consideram que a injetabilidade de uma calda está relacionada à fluidez, sendo que a calda mais injetável no solo será aquela que possuir a estabilidade mais elevada. Diante destas duas características reológicas da calda de cimento (injetabilidade x fluidez) Levis (2006), ressalta que é possível a construção das chamadas "curvas de injetabilidade", conforme a Figura 1. Esta figura demonstra a relação que existe entre a injetabilidade de uma calda e a sua viscosidade de escoamento, ou seja, a velocidade que passa através de um funil padrão (Cone de Marsh) sendo a sua estabilidade definida pelo fator de sedimentação, para diferentes fatores $\mathrm{A} / \mathrm{C}$.

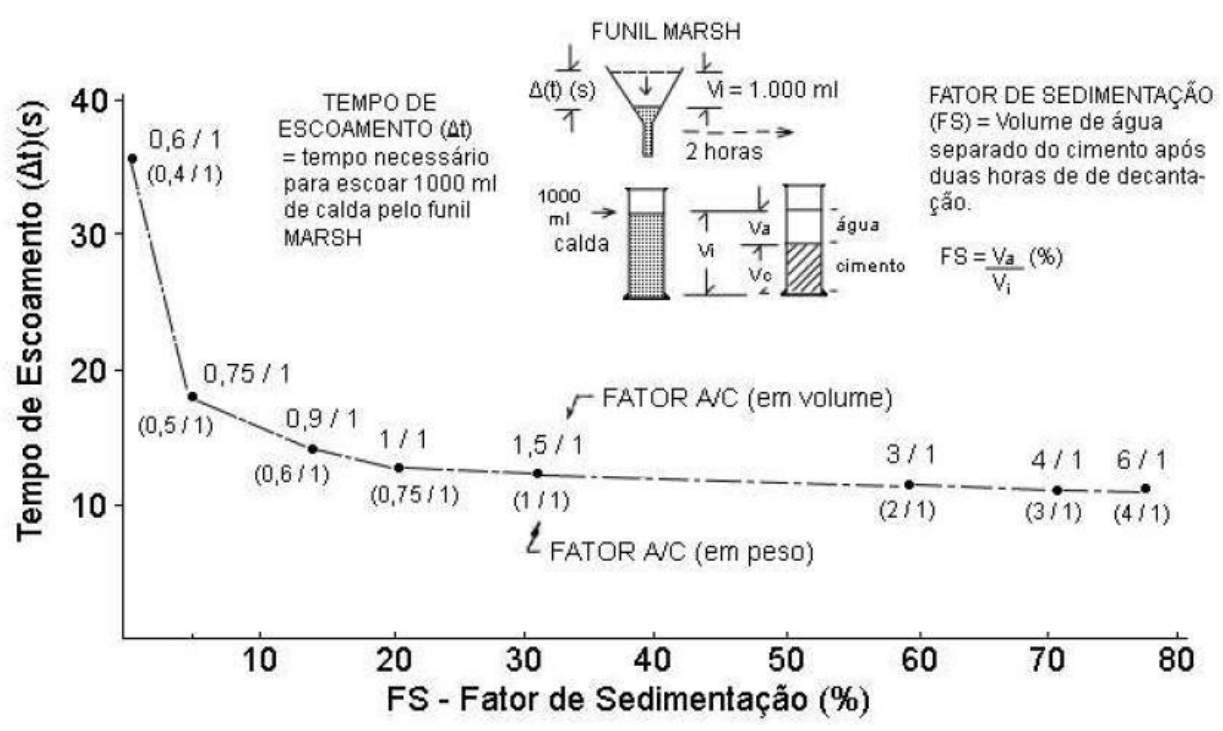

FIGURA 1: Curva de injetabilidade, laboratório de tecnologia de concreto de Salto Santiago. FONTE: Levis (2006). 
Segundo Chuaqui e Bruce (2003) a viscosidade de uma calda estável pode permanecer relativamente constante por um período de 2 a $3 \mathrm{~h}$, até ao início da presa, aumentando rapidamente até à sua conclusão, o uso de aditivos controladores de hidratação pode afetar bastante estes valores médios, bem como a existência de temperaturas extremas. Na execução de chumbadores dificilmente utilizam-se caldas ralas, apesar de serem mais fluidas e injetarem mais facilmente no solo, este tipo de injeção tornou-se comum após a concepção de chumbadores com fases, para poder ocasionar o rompimento da bainha e permitir as reinjeções. Entretanto para esta metodologia as caldas segregam mais rapidamente devido as partículas de cimento decantarem mais rápido tornando o produto final após a solidificação, mais fraco e lixiviável. Apesar das caldas grossas serem menos fluidas e injetarem com mais dificuldade havendo maiores refluxos durante a injeção, consolidam melhor a camada de solo e dão produtos finais mais resistentes após a pega, ou seja, uma bainha de chumbador com injeção dentro dos parâmetros de qualidade geotécnica, dificilmente permitirá reinjeções.

\subsection{CARACTERÍSTICA DA PRESSÃO DE INJEÇÃO}

Segundo Silva (2015), para a compressão de injeção de solos com nata de cimento e tubos manchete, tem-se que antes entender o princípio cirúrgico e não clínico, de primeiro abrir fissuras e enche-las com fluido cimentante. Estas fissuras quando abertas ao solo, submetidas a um número de fases de injeção, permitem atingir um raio de ação gerado pela calda de cimento conforme (Figura [2a]), superior ao eixo dos furos, obtendose um adensamento parcial através da redução do grau de saturação. Conforme Silva (2015) a pressão de injeção depende da permeabilidade do terreno, abertura das fissuras, viscosidade caudal e do número de fases que geram um gradiente de pressão. Este gradiente pode ser chamado de "gradiente de melhoria do solo", ou seja, incrementos de capacidade do terreno reagir à pressão com o transcorrer das diversas fases de injeção, em cada ponto de tratamento (Figura [2b]).

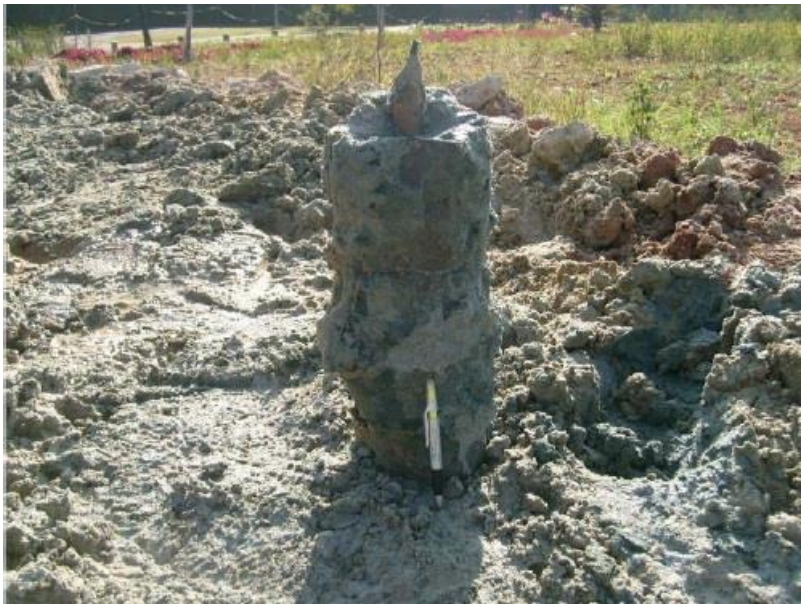

[a]

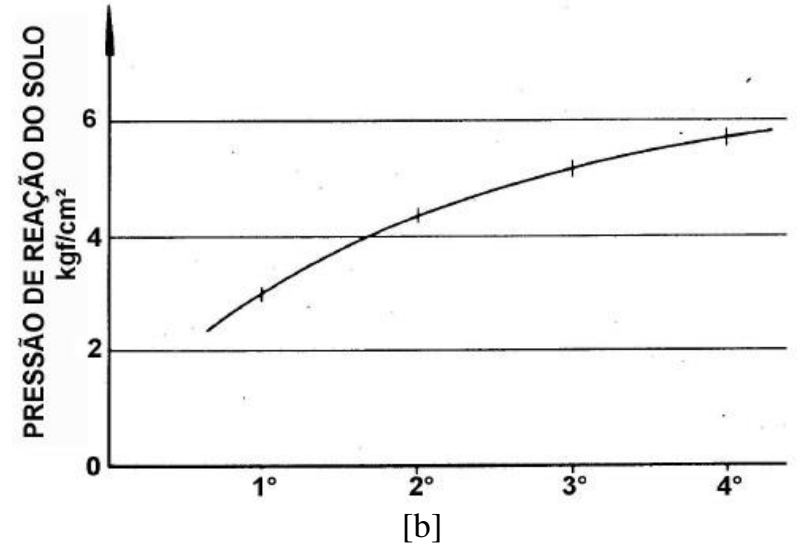

FIGURA 2: [a] Raio de ação gerado pela calda de cimento criando um conglomerado, [b] aumento médio da pressão de reação do solo em função de sucessivas fases de injeção.

FONTE: Silva (2015).

A ideia central de Silva (2015) pode ser reforçada por Weaver (2000), onde este gradiente de melhoria do solo está relacionado pelo aumento da pressão de confinamento da calda de cimento e aumento do ângulo de atrito do terreno, estimando experimentalmente em $30 \%$ o aumento do valor NSPT, sendo a pressão de injeção é determinada de acordo com a profundidade, conforme recomendado peça norma europeia e americana (Figura 3 ). 


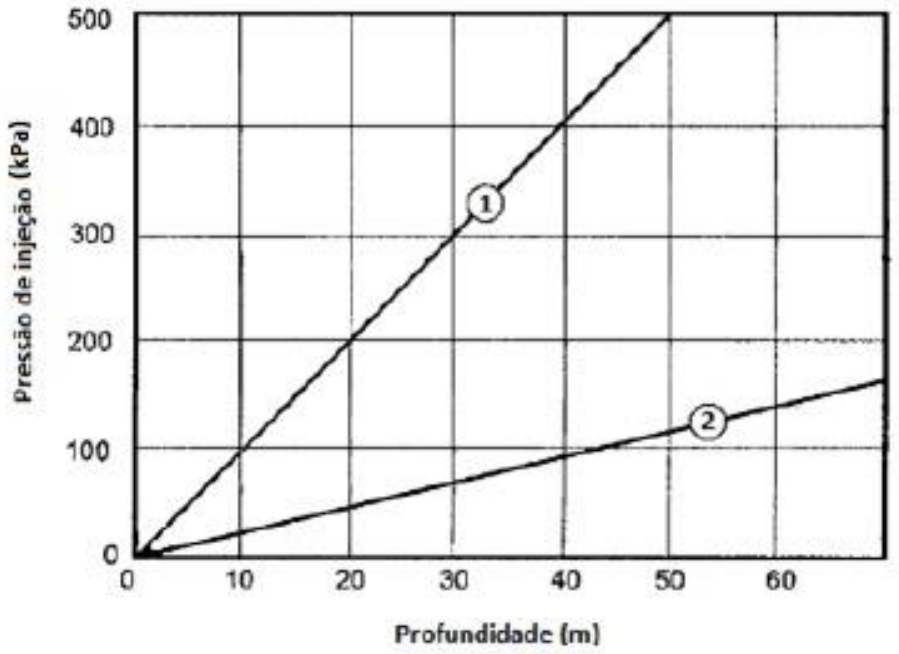

FIGURA 3: Pressão de injeção determionada pela norma européia [1] e norma americana [2].

FONTE: Weaver (2000).

Estudos realizados por Pachla (2016) e Samokhvalov et al. (2016) verificaram que o aumento das pressões de injeção estão relacionados as características físicas e mecânicas devido a compactação radial do solo, os pesquisadores verificaram que a mudança desses parâmetros do solo contribuíram para aumentar a capacidade de injeção dos solos, que está relacionada a densidade, módulo de deformação e o teor de umidade do maciço.

\subsection{ADESÃO DO SOLO COM A ESTRUTURA}

Um dos parâmetros mais importantes em projetos de solo grampeado é a resistência ao cisalhamento no contato solo-grampo (qS). Porém a busca ideal pelos valores de (qS) podem ser

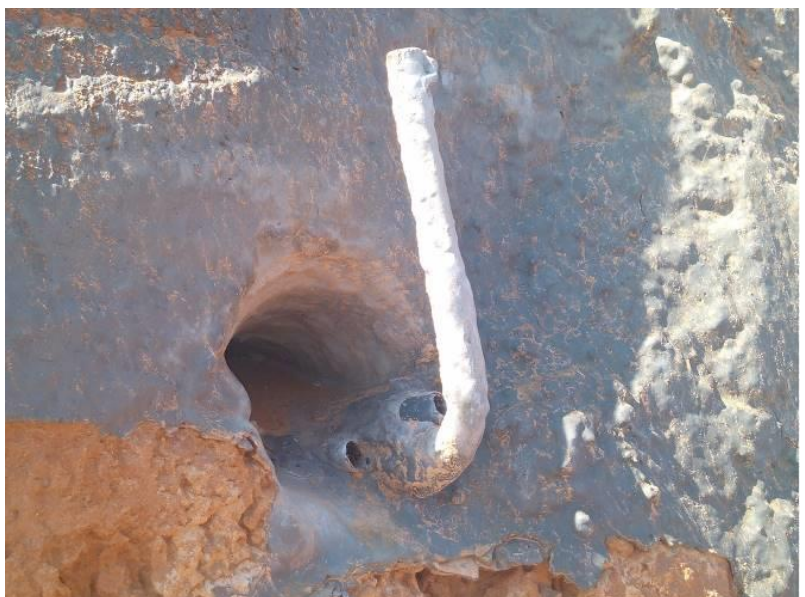

[a] comprometida pela diminuição da aderência causada pelo contato (solo-tubo de polietilenogrampo), através do aumento do número de fases de injeção, podendo ser verificada experimentalmente através de ensaio de arrancamento. De acordo com Clouterre (1991) os diferentes métodos de instalação dos chumbadores através de baixa ou alta pressão e por gravidade da calda de cimento, influenciam nos parâmetros de adesão. Esta técnica vem recebendo a prática comum independentemente do tipo de solo a padronização da instalação próxima às barras de aço, de tubos manchetados, perdidos de polietileno ou similar (Figura 4 [a]), com diâmetros de 8 a $15 \mathrm{~mm}$, providos de válvulas manchete a cada $0,5 \mathrm{~m}$, em até $1,5 \mathrm{~m}$ da boca do furo (Figura 4[b]).

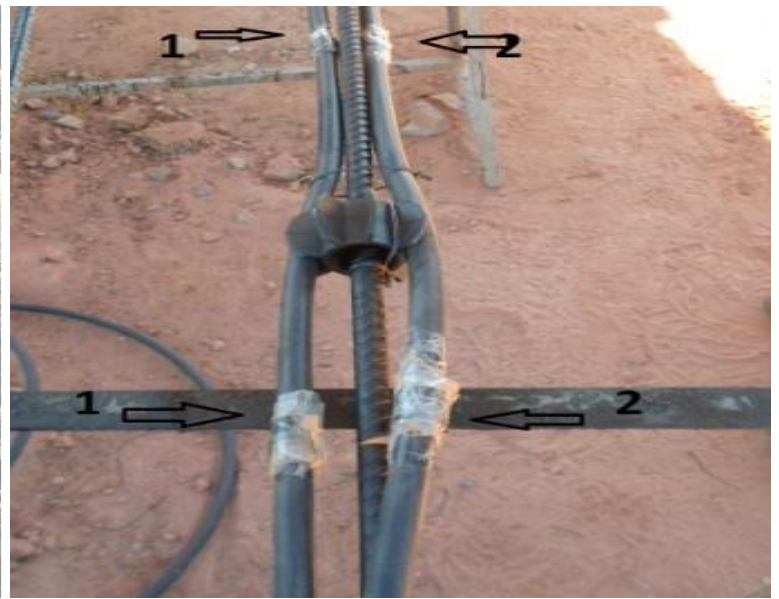

[b]

FIGURA 4: [a] Detalhe tipico de um chumbador com 2 fases de injeção, [b] válvulas manchete a cada 0,5 m. FONTE: Autoria própria. 
Estudos realizados em chumbadores através de ensaios de arrancamento por Chy e Yin (2005), Junaideen et al. (2004), Byrne et al. (1998) e Bridle (1997), demonstram faixas de variações para resistência ao arrancamento em função dos tipos de solos, recomendando os pesquisadores que os parâmetros mais c onfiáveis são encontrados durante a execução da obra, podendo sofrer alterações diante das condições do seu entorno através do teor de úmida, saturação e compactação radial do solo.

\section{PROGRAMA EXPERIMENTAL}

Para a obtenção dos parâmetros de adesão efetivos do solo grampeado em campo, na interface solo/calda, foi avaliada a influência da metodologia executiva dos chumbadores, bem como a quantidade de injeções de calda de cimento, verificando a influência das características geológicas geotécnicas do maciço de solo no parâmetro qs, a partir das distribuições de tensões verificadas durante $o$ arrancamento dos chumbadores.

\subsection{CARACTERIZAÇÃO GEOLÓGICA GEOTÉCNICA}

Os chumbadores testes foram realizados em uma obra de infraestrutura no Município de Guarulhos localizado no estado de São Paulo, estudos realizados por Agevap (2014) e Ferreira et al. (2011), demonstram que o substrato geológico do município pode ser divido em duas grandes unidades geológicas, rochas sedimentares de idade Cenozóica da Bacia de São Paulo e o seu embasamento é constituídos de rochas cristalinas metamórficas de baixo a médio grau como migmatitos, xistos, quartzitos, filitos, calcários dolomíticos e metassiltitos. Estudos realizados por Ferreira et al. (2011), demonstram que os vários graus de metamorfismo e composição muito variada conforme distribuição geográfica da região, condicionada a formação de Latossolos, Argilossolos e Gleissolos. A área da execução dos ensaios foi previamente selecionada após inspeção de fatores geológicos do terreno favoráveis a execução dos três tipos de injeção comprovados a partir de sondagens NSPT. O substrato geológico é formado por uma camada de 20 metros de solo residual de característica argilosa com lentes de camada de areia fina, os ensaios aplicados aos chumbadores foram executados entre as camadas de argila arenosa e argila siltosa localiza a cerca de 14 metros da crista do talude com NSPT variando entre 11 a 18 golpes, através das amostras recolhidas durante a investigação de subsolo foram realizados ensaios de caracterização completa obtendo limite de liquidez (LL=26\%) e limite de plasticidade (LP=54\%) e curva granulométrica conforme Figura 5 .

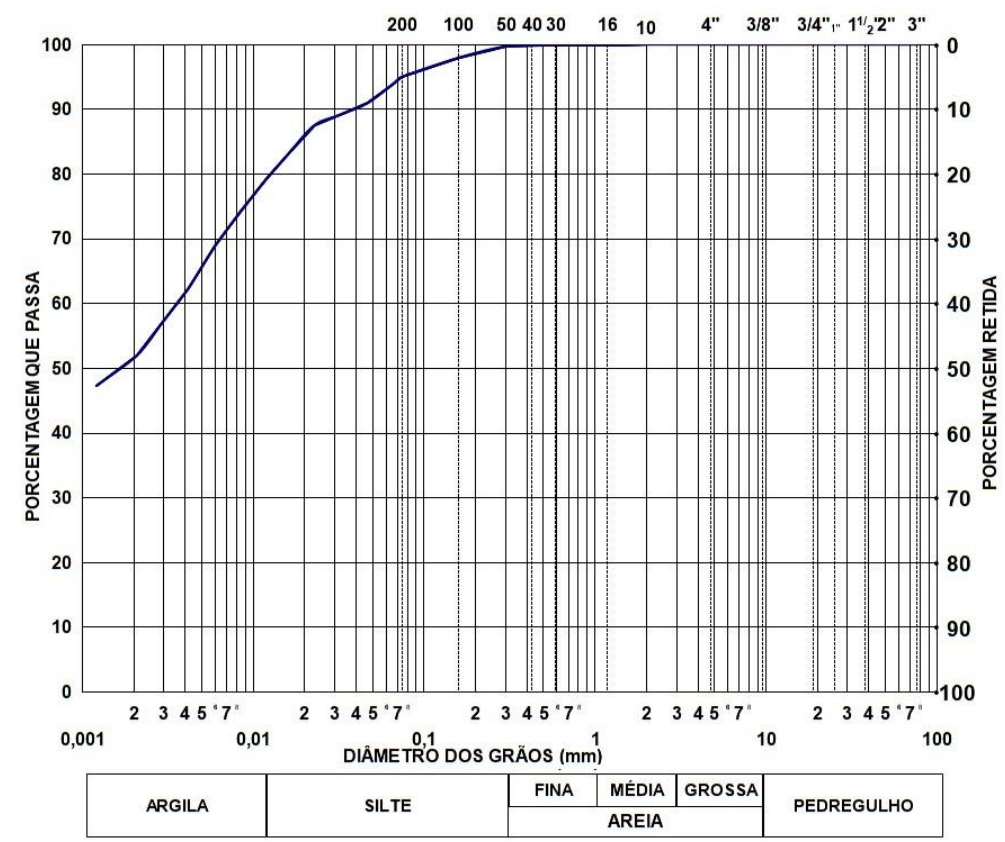

FIGURA 5: Curva granulométrica do solo local dos chumbadores testes. 
FONTE: Autoria própria.

\subsection{ENSAIO DE CAMPOS REALIZADOS}

Após um tempo mínimo de sete dias de cura da calda de cimento da última etapa de injeção, realizou-se ensaios de arrancamento em três chumbadores, ocasião em que foi testado até sua carga limite através de incrementos de cargas. Este tipo de ensaio não segue nenhuma prescrição normativa. Assim foi adotado como referência para os ensaios, a metodologia desenvolvida pela FHWA - US Department of Transportation Federal Highway Administration (2003). A metodologia descrita tem por objetivo apresentar os procedimentos mínimos necessários para obtenção em campo dos parâmetros de adesão efetivos do solo grampeado, na interface solo/calda, confirmando os valores de adesão considerados durante a fase de projeto, os resultados dos ensaios obtidos foram confrontados com os valores calculados para confirmação ou para indicação da necessidade de reavaliação.

Para realização dos ensaios adotou-se comprimento do trecho ancorado da bainha dos chumbadores em 3,0 m, para chumbadores executados em maciços com resistência à adesão solo/bainha superior a $150 \mathrm{kPa}$ e/ou diâmetro nominal superior a $10 \mathrm{~cm}$, deverão ser utilizadas barras de aço especiais cuja capacidade à tração em serviço seja suficiente para a realização do ensaio ao arrancamento. Para tanto, a capacidade à tração máxima da barra (Tmáx, barra) utilizada no ensaio atendeu a Equação 1.

Tmáx,barra $\geq$ Lb,ens * qs * $\pi * \mathrm{Db}^{*} 1,5(\mathrm{~m}) \quad$ Eq. [1]

Em que:

Lb,ens = comprimento ancorado da bainha $(m)$;

qs = adesão solo/bainha (Kpa);

$\mathbf{D b}=$ diâmetro da bainha $(\mathrm{m})$.

A força de ensaio teórica levou em consideração a força admissível teórica que é dada pela Equação 2, onde (Lb,ens) é comprimento do trecho ancorado efetivo, medido na execução dos chumbadores a serem ensaiados, sendo que o comprimento previsto de $3 \mathrm{~m}$ não deverá variar mais do que $10 \%(2,70 \mathrm{~m} \leq \mathrm{Lb}$,ens $\leq 3,30 \mathrm{~m})$.

$$
\text { Fens: Lb,ens } * \text { qs } * \pi * \text { Db } \quad \text { Eq. [2] }
$$

A montagem do ensaio garantiu um comprimento livre mínimo de $1 \mathrm{~m}$ na extremidade de aplicação da força de ensaio, garantido também um afastamento mínimo da extremidade da bainha à placa de reação de $20 \mathrm{~cm}$. A resistência ao cisalhamento de adesão (qs) é representada pela Equação 3 dividindo-se a força máxima aplicada ao final do ensaio (Fens,máx) pela área teórica de superfície da bainha do chumbador ensaiado.

qs: Fens,máx / Ab (área da bainha) $=$ $=$ Fens,máx $/\left(\pi^{*} \mathrm{Db}\right) *$ Lb,ens)

Durante os ensaios o carregamento dos chumbadores foi submetido a incrementos prédeterminados até a ruptura ou 1,5 vezes a força de ensaio (Fens), conforme a Tabela 1.

\begin{tabular}{|l|c|}
\hline \multicolumn{2}{|c|}{ TABELA 1: Plano de carga de ensaio para } \\
chumbadores.
\end{tabular}

FONTE: Autoria própria.

O ensaio de fluência é realizado para uma carga constante e pré-determinada com registro de deslocamentos em uma série de intervalos de tempo. A curva de deslocamento e função do tempo é construída em escala logarítmica e comparada de acordo com os critérios de aceitação. $O$ ensaio de fluência deverá ser realizado durante o ensaio de qualificação na carga de 0,75 Fens, os deslocamentos devem ser registrado da seguinte forma: nos tempos 1 minuto, $2,3,5,6,10,20,30,50$ e 60 minutos, além da força de ensaio ser mantida constante com variação máxima de $2 \%$ através da leitura de 
O ensaio de qualificação é considerado aprovado quando atender aos seguintes critérios: a ruptura não deverá ocorrer com carga menor do que 1,5 vezes a força de ensaio (1,5 Fens), a ruptura é caracterizada pela impossibilidade de aplicar incrementos de carga sem deslizamento da bainha. Nos ensaios de fluência o deslocamento total máximo durante a aplicação da carga constante entre os minutos 6 e 60 não deve superar $2 \mathrm{~mm}$. As leituras de deslocamento indicadas em gráfico com tempo em escala logarítmica devem apresentar taxas lineares em função do tempo ou decrescentes. O deslocamento total $(\Delta \mathrm{L})$ medido ao final do ensaio com a aplicação da força máxima de ensaio (Fens,máx) deve exceder $80 \%$ do deslocamento elástico do comprimento livre.

Este critério visa garantir que a carga aplicada nos chumbdores tenha sido transferida para o solo ao longo do trecho ancorado de acordo com a Equação 4.

$\Delta \mathrm{L} \geq \Delta \mathrm{Lmin}: 0,8 *$ Fens, máx * LL / E * As Eq. [4] Em que:

Fens, máx = Força máxima de ensaio (kgf);

$\mathbf{L L}=$ Comprimento livre $(\mathrm{m})$;

$\mathbf{E}=$ Módulo de Young da barra de aço $\left(\mathrm{kgf} / \mathrm{m}^{2}\right)$;

As = área nominal da seção da barra de aço $\left(\mathrm{mm}^{2}\right)$.

\subsection{CHUMBADOR TESTE}

Foram realizados três chumbadores testes denominados (E1, E2 e E3), executados com bainha (E1), bainha e uma fase de injeção (E2) e bainha mais duas fases de injeção (E3), visando a contribuição da injeção de calda de cimento na interação solo-chumbador. Durante a montagem para cada ensaio foram utilizadas duas barras rosqueáveis com $6,0 \mathrm{~m}$, unidas através de luvas, sendo que nos últimos $3,0 \mathrm{~m}$ ancorados foram utilizados duas mangueiras de polietileno dispostas para cada fase de injeção. Para evitar o contato com solo e calda de cimento, ao trecho livre de $8,0 \mathrm{~m}$ foi acoplado um tudo de PVC de 3 Pol. vedado com massa de calafetar em sua extremidade obstruindo assim qualquer possibilidade de contato com a célula de carga.

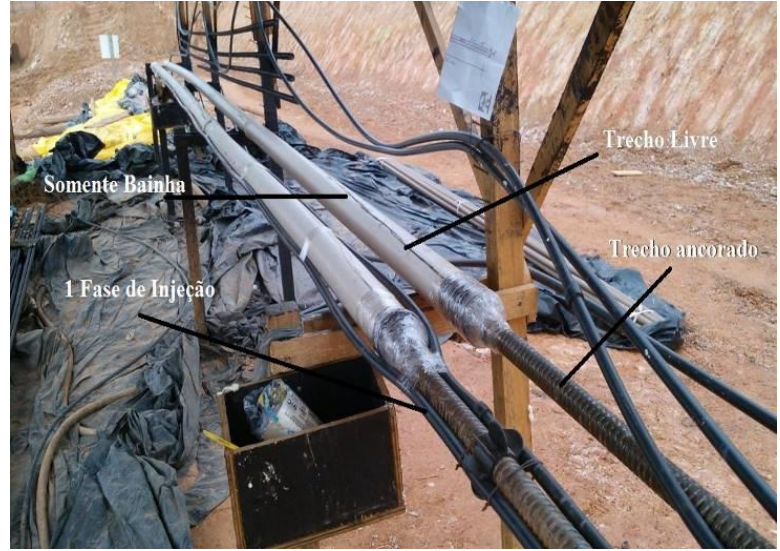

FIGURA 6: Detalhes da montagem dos chumbadores teste para ensaio de arrancamento. FONTE: Autoria própria.

\subsection{SISTEMA DE PERFURAÇÃO}

Um dos grandes fatores relacionado ao desempenho dos chumbadores está relacionado ao sistema de perfuração. A prática de perfuração de forma sequencial vem se tornando cada vez mais comum nos serviços de estabilização, comprometendo a estrutura do solo através da abertura de fissuras e a comunicação com furos vizinhos. Os chumbadores testes foram realizados dentro do ciclo de produção com perfurações alternadas (Figura 7 [a]), com ar comprimido com pressões em torno de $10 \mathrm{Kgf} / \mathrm{cm}^{2}$, onde após perfurados adotou-se um critério de parada para à saída de resíduos nos últimos trechos para evitar qualquer contato com a calda de injeção, além do controle preciso do grau de inclinação, possibilitando total preenchimento anelar da calda (Figura 7 [b]).

\subsection{SISTEMA DE INJEÇÃO}

Para a execução das injeções o esquema de preparo da calda de cimento foi realizado através de uma central próxima a área teste, por meio de misturador de alta turbulência provido de turbina, com rotação mínima de 1.700 rpm, capaz de preparar calda de cimento em quantidades suficiente para suprir a bomba injetora fornecendo a homogeneidade adequada à mistura. $O$ controle da calda foi realizado através do ensaio de vida útil e fluidez para cada chumbador, além de ensaios de compressão axial obtendo a resistência média através da ruptura de 6 corpos de prova, a Tabela 2 demonstra os resultados médios obtidos das 
calda de cimento durante a injeção (Figura 6).

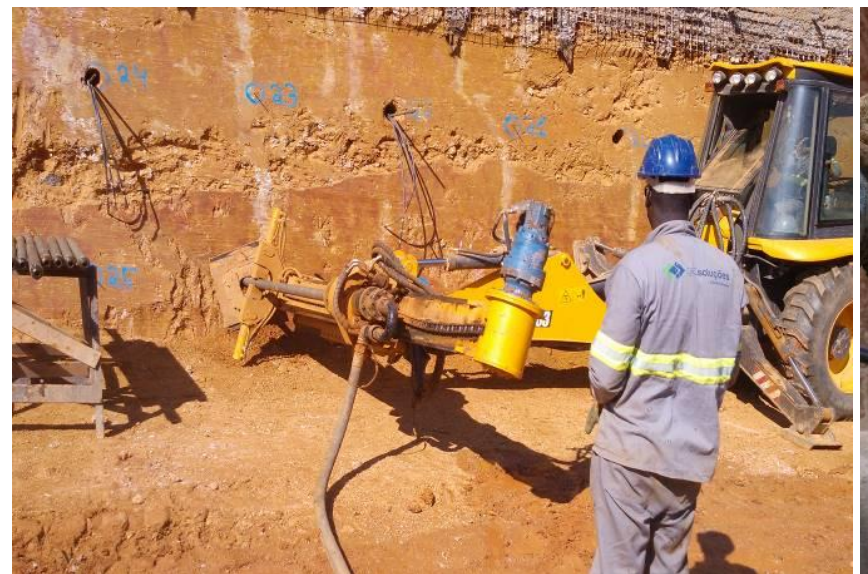

[a] caldas de cimento.

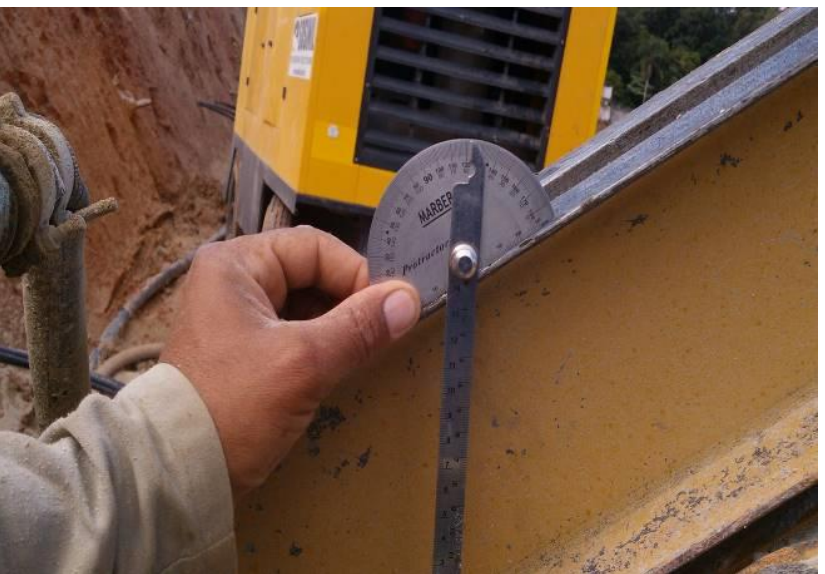

[b]

FIGURA 7: [a] Execução de chumbador teste, [b] Controle do grau de perfuração.

FONTE: Autoria própria.

\begin{tabular}{|c|c|c|c|c|c|c|c|}
\hline \multicolumn{4}{|c|}{ Injeção (kg) } & \multirow{2}{*}{$\begin{array}{l}\text { Exsudação } \\
\text { média das } \\
\text { caldas (\%) }\end{array}$} & \multirow{2}{*}{$\begin{array}{c}\text { Resistência } \\
\text { Bainha } \\
\text { (Mpa) }\end{array}$} & \multirow{2}{*}{$\begin{array}{c}\text { Resistência } \\
\text { 1a fase de } \\
\text { injeção (Mpa) }\end{array}$} & \multirow{2}{*}{$\begin{array}{c}\text { Resistência } \\
\text { 2a fase de injeção } \\
\text { (Mpa) }\end{array}$} \\
\hline Ensaio & Bainha & $\begin{array}{c}1 \underline{\mathbf{a}} \\
\text { Fase }\end{array}$ & $\begin{array}{c}2^{\mathrm{a}} \\
\text { Fase }\end{array}$ & & & & \\
\hline E1 & 249 & 0 & 0 & 0,15 & 28,8 & 0 & 0 \\
\hline E2 & 185 & 45 & 0 & 0,20 & 28,6 & 25,9 & 0 \\
\hline E3 & 200 & 63 & 20 & 0,29 & 27,1 & 28,4 & 28,2 \\
\hline
\end{tabular}

FONTE: Autoria própria.

Para o preenchimento da bainha a injeção foi realizada de forma ascendente, com calda de cimento fator a/c 0,5 e após o período de 12 horas concluíram as reinjeções através de tubo de injeção perdido de polietileno (Figura 8 [a]), anotando-se a pressão máxima de injeção e o volume de calda absorvida. As pressões de reinjeção máximas da ordem de $10 \mathrm{kgf} / \mathrm{cm}^{2}$ foram controladas através de dois estabilizadores de pressão (Figura $8[\mathrm{~b}]$ ), um ligado a bomba de injeção e outro próximo aos chumbadores, para verificar de forma eficiente as leituras.
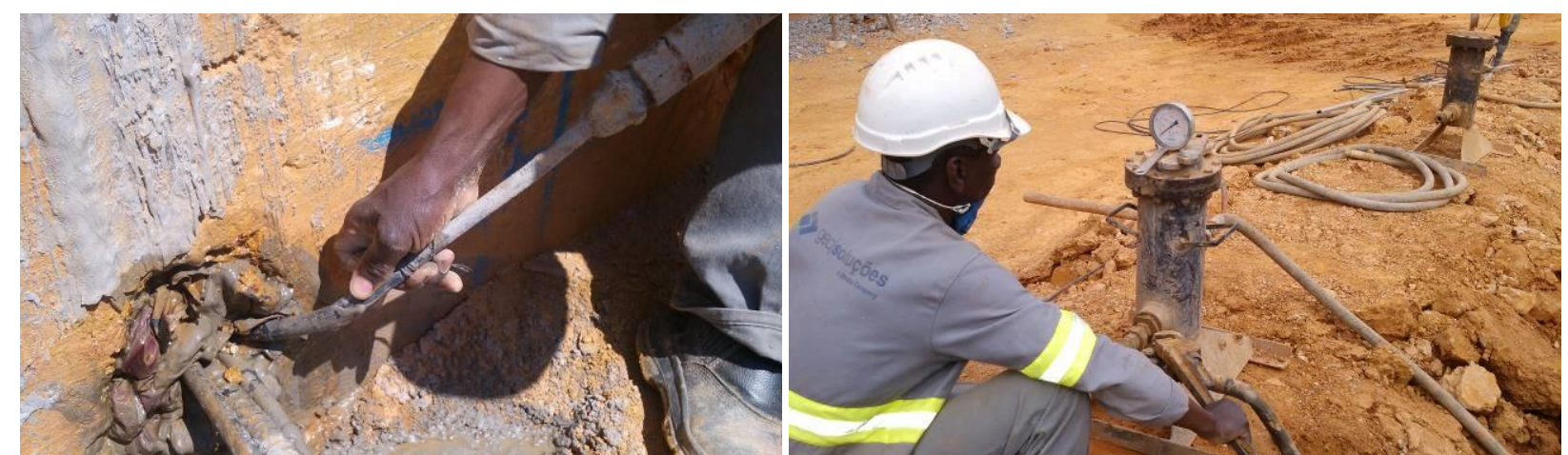

FIGURA 8: [a] Detalhe da injeção em fases, [b] Controle da pressão de injeção com pressão máxima $10 \mathrm{Kgf} / \mathrm{cm}^{2}$. FONTE: Autoria própria. 


\subsection{CONCRETO PROJETADO}

$\mathrm{Na}$ face do talude teste foram executados concreto projetado via úmida, sobre duas camadas de tela em duas etapas, realizando um cobrimento mínimo de $5 \mathrm{~cm}$ a cada aplicação, com espessura final de $15 \mathrm{~cm}$, em uma área de 5,00 × 3,5 m, para cada chumbador teste. Durante a aplicação foram realizados moldagem de placa (Figura 9), para verificação da resistência a compressão axial, conforme NBR 13070-(ABNT, 2012) e NBR 14026 (ABNT, 2012).

Para garantir que a placa de reação na face do projetado permitisse a distribuição de incrementos de carga durante o ensaio, durante a projeção foram utilizados aditivos a base de acelerador de pega com dosagem de $2,37 \mathrm{~kg} / \mathrm{m}^{3}$ e plastificante em $2,58 \mathrm{~kg} / \mathrm{m}^{3}$, atingindo valores maiores do que projeto previsto em $30 \mathrm{MPa}$, conforme demonstrado na Tabela 3.

\section{ENSAIO DE ARRANCAMENTO}

Na realização de ensaios de tração em chumbadores ancorados no terreno, tendo como base as diretrizes apontadas na metodologia conforme citado no item 4 , mediante o procedimento de inspeção visual preliminar realizado nas interfaces chumbador/muro, previamente ao início dos ensaios visando detectar eventuais anomalias e/ou dados relevantes. A execução dos carregamentos foi realizada com a utilização de conjunto hidráulico devidamente calibrado (Figura 10 [a]), monitorados com a utilização de extensômetros com precisão de leitura igual a 0,01 mm (Figura 10 [b]).

A Tabela 4 demonstra todos os parâmetros calculados dos chumbadores para os testes.

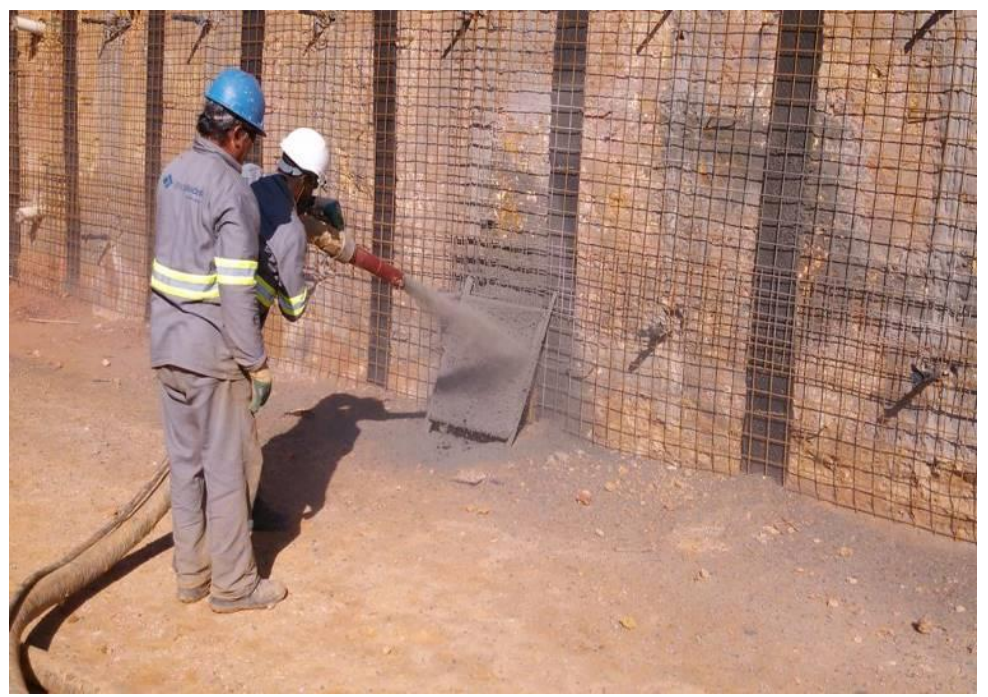

FIGURA 9: Moldagem de placa de concreto projetado para verificação de resistência axial. FONTE: Autoria própria.

\begin{tabular}{|c|c|c|c|c|c|}
\hline $\begin{array}{l}\text { Abatimento } \\
(\mathrm{mm})\end{array}$ & $\begin{array}{l}\text { Idade } \\
\text { (Dias) }\end{array}$ & $\begin{array}{l}\text { Diâmetro } \\
(\mathbf{m m})\end{array}$ & $\begin{array}{l}\text { Corpo de prova } \\
\text { (nㅇ) }\end{array}$ & $\begin{array}{c}\text { Resistência } \\
\text { (Mpa) }\end{array}$ & $\begin{array}{l}\text { Resistência } \\
\text { Média } \\
\text { (Mpa) }\end{array}$ \\
\hline \multirow{6}{*}{250} & \multirow{2}{*}{1} & \multirow{6}{*}{100} & 1 & 36,7 & \multirow{2}{*}{35,40} \\
\hline & & & 2 & 34,0 & \\
\hline & \multirow{2}{*}{3} & & 3 & 42,1 & \multirow{2}{*}{42,30} \\
\hline & & & 4 & 42,5 & \\
\hline & \multirow{2}{*}{7} & & 5 & 53,6 & \multirow{2}{*}{53,20} \\
\hline & & & 6 & 52,7 & \\
\hline
\end{tabular}




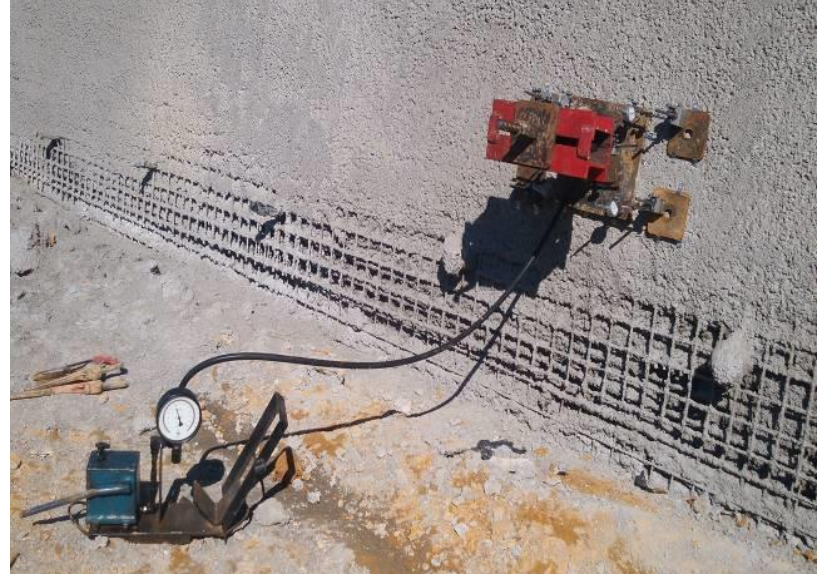

[a]

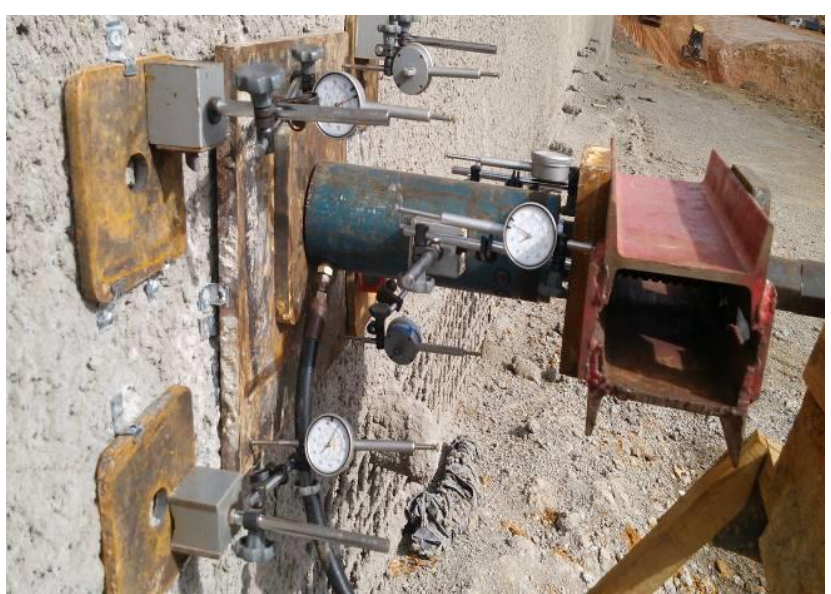

[b]

FIGURA 10: [a] Macaco hidráulico manual devidamente calibrado, [b] vista geral dos extensômetros.

FONTE: Autoria própria.

\begin{tabular}{|l|c|}
\hline \multicolumn{2}{|c|}{ TABELA 4: Dados do chumbador ensaiado e Parâmetros Calculados. } \\
\hline Comprimento ancorado da bainha (Lb, ens) & $3,0 \mathrm{~m}$ \\
\hline Comprimento livre (LL) & $8,0 \mathrm{~m}$ \\
\hline Resistência de adesão da bainha (qs) & $70 \mathrm{Kpa}$ \\
\hline Diâmetro teórico da bainha (DB) & $0,100 \mathrm{~m}$ \\
\hline Especificação da barra & Monobara TOR 23B \\
\hline Módulo de elasticadade da barra (E) & $21.000 \mathrm{kgf} / \mathrm{m}^{2}$ \\
\hline Área nominal da sção da barra de aço (AS) & $791 \mathrm{~mm}^{2}$ \\
\hline Fens & $6,597 \mathrm{kgf}$ \\
\hline Fens máxima & $9,896 \mathrm{kgf}$ \\
\hline$\Delta$ Lmin & $3,81 \mathrm{~mm}$ \\
\hline
\end{tabular}

\subsection{CONSIDERAÇÕES SOBRE O ENSAIO}

Os chumbadores E1, E2 e E3 ensaiados com base na metodologia para ensaio de arrancamento citada no item 3 obtiveram as seguintes características. Após a aplicação de 1,5 da força de ensaio, não foram constatados a ruptura dos 3 chumbadores, caracterizada pela possibilidade de aplicar incrementos de carga sem deslizamento da bainha. O chumbador E1 superou $80 \%$ do deslocamento elástico do comprimento livre, sendo a carga aplicada transferida para o solo ao longo do trecho ancorado (Figura 11).
O deslocamento total $(\Delta \mathrm{L})$ medido ao final do ensaio E2 e E3, com a aplicação da força máxima de ensaio (Fens,máx) não superaram 80\% do deslocamento elástico do comprimento livre, não garantindo que a carga aplicada nos chumbadores tenha sido transferida para o solo ao longo do trecho ancorado (Figura 12 e 13).

Todos os chumbadores durante o ensaio de fluência, o deslocamento total máximo durante a aplicação da carga constante entre os minutos 6 e 60 não superaram o deslocamento de $2 \mathrm{~mm}$ conforme Figura (14), se enquadrando dentro das recomendações da FHWA (2003). 


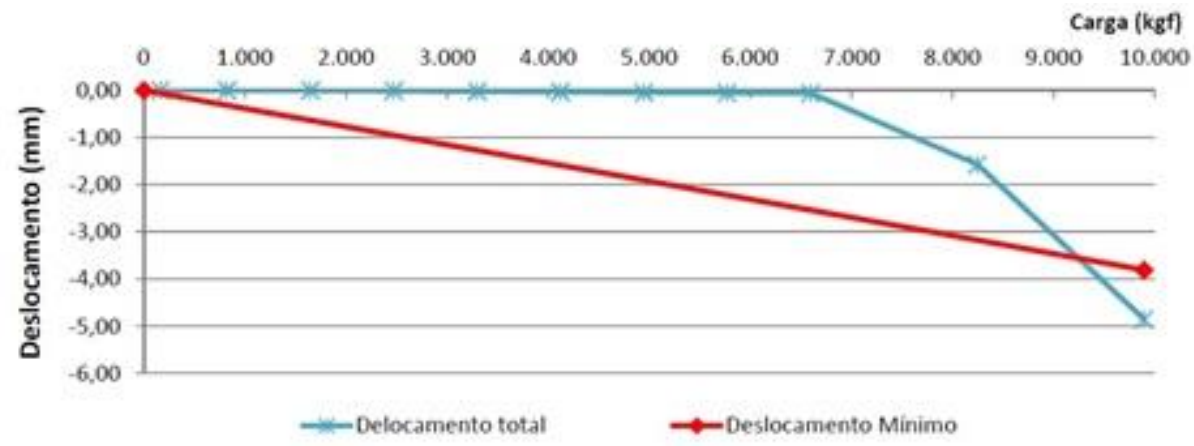

FIGURA 11: Ensaio de qualificação - gráfico deslocamento x carga do chumbador E1.

FONTE: Autoria própria.

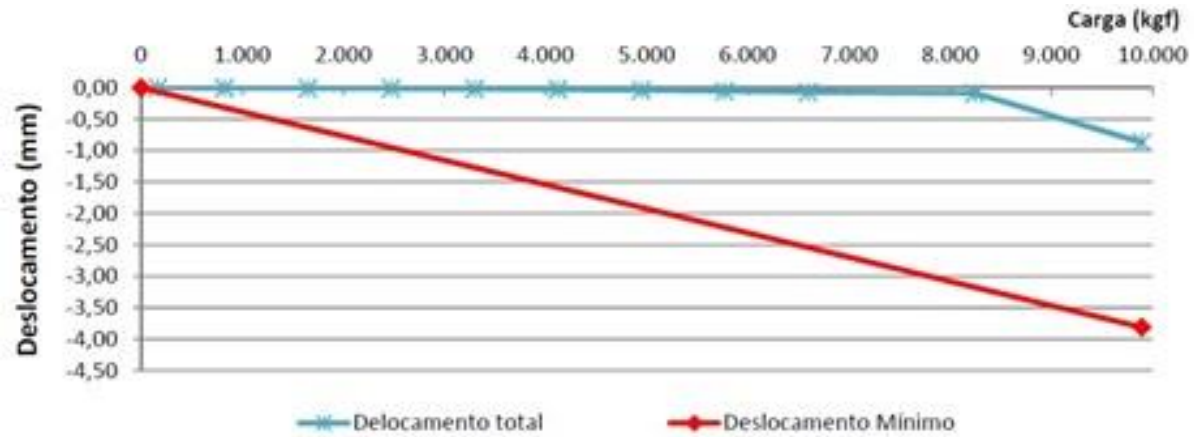

FIGURA 12: Ensaio de qualificação - gráfico deslocamento x carga do chumbador E2.

FONTE: Autoria própria.

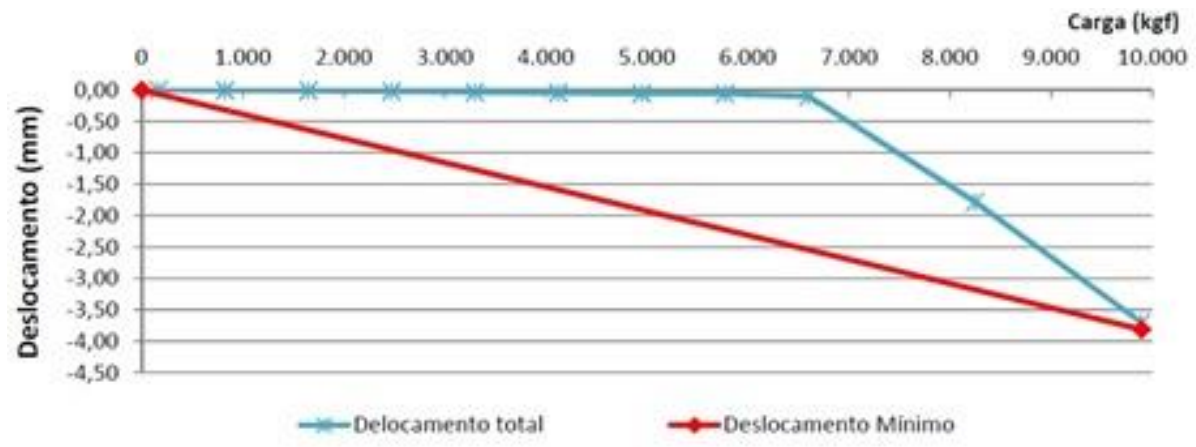

FIGURA 13: Ensaio de qualificação - gráfico deslocamento x carga do chumbador E3.

FONTE: Autoria própria.

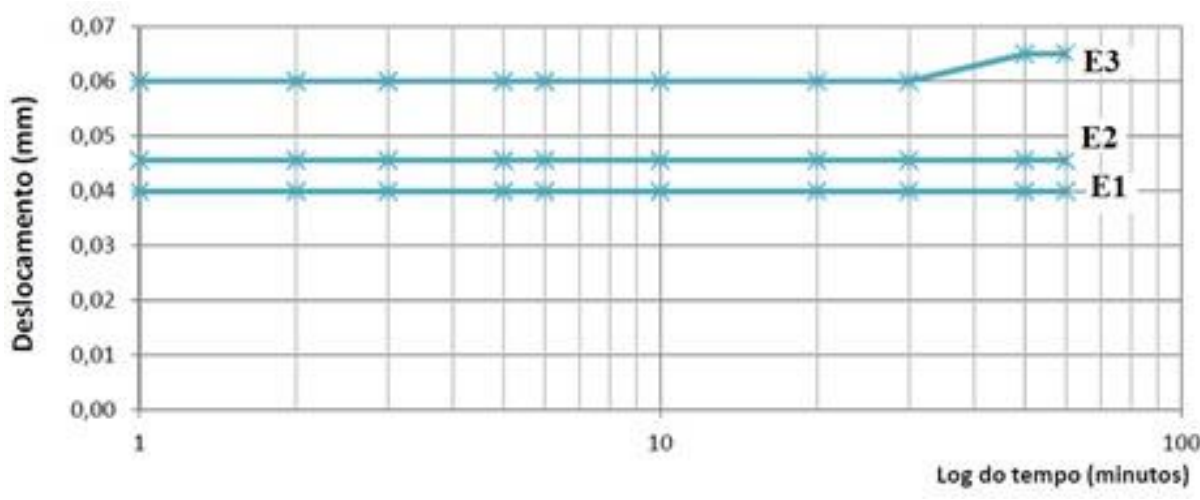

FIGURA 14: Ensaio de fluência constando a média dos deslocamentos E1, E2 e E3.

FONTE: Autoria própria. 
Diante dos resultados apresentados, somente o chumbador E1, injetado com bainha atendeu todos os critérios de aceitação descritos na metodologia de ensaio de arrancamento, verificando a independência entre o parâmetro adesão (qs) e o volume de calda de cimento. Os gráficos demonstram que a transferência de carga dos chumbadores E2 e E3 para o maciço, foi comprometida pela aderência entre a interação com o solo, tendo em vista que estes chumbadores receberam os maiores volumes de calda de cimento, sendo a quantidade de cimento injetada prejudicada pela falta de adesão barracalda-solo gerada, ocasionada pelos tubos de injeção de polipropileno. Demonstrando que parâmetros encontrados in loco estão coerentes com os calculados, como a técnica não está enquadrada em nenhuma norma, podendo a metodologia adotada ser uma alternativa para estimar a resistência de adesão na fase de prédimensionamento da obra.

\section{CONSIDERAÇÕES FINAIS}

Os ensaios realizados por meio do sistema de chumbadores ancorados em solos de baixa permeabilidade apresentam como principal contribuição critérios básicos para estabelecer o tratamento do maciço, através da injeção em fase única "bainha", visando manter a concepção do soil nailing uma técnica onde necessita-se de rápida execução, empregada ao se deparar com uma situação de escorregamento ou diante de estabilização de taludes. Tratando o sistema executivo como uma técnica economicamente viável buscando o favorecimento geotécnico, as fases de injeções não devem ser generalizadas antes de avaliar os parâmetros dos solos. A indução da injeção do maciço através da diminuição do fator $a / c$, para proporcionar o rompimento da bainha e possibilitar a injeção de fases, compromete a interação solo-estrutura. A melhoria da capacidade de carga através da técnica do incremento do número de injeções, está relacionada diretamente a solos de baixa resistência como aterro, solos moles e de alta permeabilidade, contribuindo na mudança de seus parâmetros como coesão e atrito.

Para manter a contribuição da técnica garantindo o seu baixo custo, versatilidade de adaptação à geometrias variadas, necessita-se manter as diretrizes de acordo com as características do local, o qual baseia-se no comportamento geológico do maciço, e através dos procedimentos técnicos como: linhas de injeção, espaçamento entre os furos, pressões de injeção, volumes injetados, tipos de traço de calda e critério de recusa da calda de cimento. Considerando que alguns fatores podem ser essências nos valores de qS como: as características do terreno, propriedades de adesão solo- grampo, método de perfuração e de limpeza do furo além características da calda de cimento.

O programa experimental contribui para o desenvolvimento de parâmetros de memória de cálculo e metodologias de ensaios, visando a obtenção da adesão em chumbadores executados em solos coesivos, demonstrando que a quantidade de calda de cimento injetada pode ser prejudicada pelo número de tubos de fases de injeção ao longo das barras de aço.

\section{REFERÊNCIAS BIBLIOGRAFICAS}

AGÊNCIA DA BACIA DO RIO PARAÍBA DO (AGEVAP). Plano integrado de recursos hídricos da bacia hidrográfica do rio Paraíba do Sul e planos de ação de recursos hídricos das bacias afluentes. Rio de Janeiro: CEIVAPA; AGEVAP; COHIDRO, 2014. 367 p.

AZEVDO, A. A.; OLIVEIRA, A. M. S.; SOARES, L. Injeção de vedação em fundações basálticas de barragens de gravidade. In: Congresso Brasileiro de Geologia de Engenharia, 1978, São Paulo/SP. São Paulo, 1978. v.1, p.17-33.

BRIDLE, R. J.; DAVIES, M. C. R. Analysis of soil mailing using tension and shear: experimental observations and assessment. Geotechinical Enginewering. V. 125, p. 155-167, jul. 1997.

BYRNE, R. J.; COTTON, D.; PORTERFIELD, J., WOLSCHAG, C., UEBLACKER, G. Manual for design and construction monitoring of soil nail wall. Report. No. FHWA-A-96- 
069R. Washington, 568p. 1998.

CHU, L. M.; YIN, J. H. A laboratory device to test the pull-out behavior of soil nails. Geotechnical Tsting Journal. West Conshohocken. V. 28. No. 5. P.499-513. Set. 2005

CHUAQUI, M.; BRUCE, D. A. Mix Design and Quality Control Procedures for High Mobility Cement Based Grouts. In-Grouting and Ground Treatment, Proceedings of the Third International Conference, 1012 February, New Orleans, LA, Geotechnical Special Publication No.120, pp. 1153-1168. (2003).

FERREIRA, C. C; CAMPOS, D. C. de C.; OLIVEIRA, E. S. Caracterização Geológica de Guarulhos. Revista Brasileira de Geociências, v.7, 2011.

JUNAIDEEN, S.; THAM, L. G.; LEE, C. F.; YUE, Z. Q.; LAW, $\mathrm{K}$. T. Laboratory study of soil-nail interaction in loose, completely decomposed granite. Canadian Geotechical Journal, No. 41, p. 274-286, 2004.

LEVIS, S. D. Verificação da eficácia dos sistemas de vedação e drenagem em fundações de barragem de concreto. 2006. 195p. Dissertação (Mestrado em Mecânica das Rochas) - Escola de Engenharia de São Carlos da Universidade de São Paulo, São Carlos.

PACHLA, $\mathrm{H}$. Conditions of proper interaction of lowpressure injection piles (LIP) with structure and soil, carrying capacity of pile anchorage in foundation. Studia Geotechnica et Mechanica, v. 38, n. 4, p. 33-49, 2016.

RABCEWICZ, L. V. The New Austrian Tunnelling Method. Revista Water Power p.453-457 Novembro 1964, p.511-515, Dezembro - 1964, p.19-22, Janeiro 1965.

SAMOKHVAIL, M., ZAZULYA, J., MELNIKOV, R., MIRNOV, V. Design Calculation of Drill-Injection Piles with Controlled Broadening and Silty-Clayed Soil Foundation Basic Interaction Parameters. In: MATEC Web of Conferences. EDP Sciences, 2016. p. 01009.

SILVA, R. R. C. da. Contribuição para escavação em solo aluvionar através da técnica de injeção de consolidação. In: SEFE- Seminário de Engenharia Profundas Especiais, 2015, São Paulo - SP.

SILVA, R. R. C. da. Comportamento de Chumbadores Ancorados em rocha, na Região de Campos do Jordão. In: COBRANSEG. Congresso Brasileiro de Mecânica dos Solos e Engenharia Geotecnica., 2011.

US DEPARTAMENT OF TRANSPORTATION FEDERAL HIGHWAY ADMINISTRATION FEDERAL - (FHWA). Geotechnical engineering circular No7 - Soil nail walls. Março 2003. 424p.
WEAVER, K. D. A Critical Look at Use of "Rules of Thumb"for Selection of Grout Injection Pressures. In: Advances in grouting and ground modification. 2000. p. $173-180$. 